\title{
Notas para uma compreensão ampliada do conceito de ideologia dominante
}

\section{Theoretical remarks for an expanded understanding of dominant ideology}

\section{Leonardo Bacher medeiros* Leonardo Granato**}




\section{RESUMO}

Este artigo tem por finalidade discutir elementos teóricos para uma interpretação ampliada do conceito de ideologia dominante na formação social capitalista. Para isso, parte do pressuposto de que o conceito de ideologia é um objeto de análise complexo, e que, apesar disso, predomina nos estudos sociais uma abordagem restritiva sobre seu significado (uma acepção negativa ou neutra) em relação ao Estado capitalista, limitando a análise das relações sociais envolvidas no conflito político a ser analisado. Em razão disso, por meio da revisão bibliográfica, este trabalho busca elementos teóricos para uma compreensão ampliada de ideologia dominante, especialmente nas formulações de Karl Marx, Friedrich Engels e Nicos Poulantzas. A abordagem deste artigo é baseada, inicialmente, na interpretação dos sentidos atribuídos ao conceito de ideologia por Marx e Engels. Em seguida, analisa seus significados como estrutura regional e conceito relacional na obra de Poulantzas. Com base nas contribuições desses autores, conclui que há elementos para uma interpretação ampliada do conceito de ideologia dominante. Particularmente, compreende que essa interpretação se compõe de pelo menos duas dimensões de análise: uma primeira, que aborda seus pressupostos estruturais (efeitos de isolamento e unidade), e uma segunda, que identifica sua característica relacional e suas práticas concretas (o discurso político, as práticas jurídicas, as relações de trabalho etc.) na formação social.

Palavras-chave: Ideologia dominante. Estado capitalista. Ideologia capitalista.

\section{ABSTRACT}

This article aims to discuss theoretical elements for an expanded interpretation of the concept of dominant ideology in the capitalist social formation. In order to do this, it starts from the assumption that the concept of ideology is a complex object of analysis and that, nevertheless, a restrictive approach to its meaning (a negative or neutral meaning) prevails in social studies in relation to the capitalist State, limiting the analysis of the social relations involved in the political conflict to be analyzed. Because of that, through a literature review, this paper looks for theoretical elements for an expanded understanding of dominant ideology, especially in the formulations of Karl Marx, Friedrich Engels and Nicos Poulantzas. The approach in this paper is based on the interpretation of the meanings attributed to the concept of ideology by Marx and Engels. Then, it analyzes its meanings as a regional structure and relational concept in the work of Poulantzas. Based on contributions of these authors, it concludes that there are elements for an expanded interpretation of the concept of dominant ideology. In particular, it understands that this interpretation is composed by at least two dimensions of analysis: a first one addresses its structural assumptions (effects of isolation and unity); a second one identifies its relational characteristic and its concrete practices (political discourse, legal practices, labor relations etc.) in the social formation.

Keywords: Dominant ideology. Capitalist state. Capitalist ideology. 


\section{INTRODUCC̣̃O}

O estudo do poder político e das suas transformações ao longo da história deve ser guiado pelo exame do conjunto das relações complexas que acompanham esse poder, reunindo não apenas as lutas políticas nos campos econômico e político, mas também a sua dimensão ideológica. Esse fator foi introduzido no debate teórico notadamente por Antonio Gramsci com a noção de Estado ampliado, e foi retomado de forma contundente nas sistematizações teóricas sobre o Estado na Europa nas décadas de 1960 e I970, especialmente no pensamento de autores como Louis Althusser ${ }^{1}$ e Nicos Poulantzas².

Este último autor em particular, em sua obra magna Pouvoir politique et classes sociales, de $1968^{3}$, propõe a articulação entre as ideologias (geral e particulares) e explica seus efeitos para o Estado capitalista. Já em sua última obra, L'État, le pouvoir, le socialisme, de 1978, ao enfatizar a problemática da luta de classes no interior do aparelho do Estado ${ }^{4}$, Poulantzas nos fornece subsídios para pensarmos o conceito de ideologia também como um conceito relacional.

Por diferentes gradações e enfoques, ao longo da história da teoria política, o conceito de ideologia se apresenta com maior ou menor ênfase, mas sempre como uma variável particularmente importante para a compreensão do Estado capitalista. Contemporaneamente, predomina nos estudos sociais sobre o tema uma abordagem restritiva sobre seu significado (uma acepção negativa ou neutra) em relação ao Estado capitalista, o que, tendo em conta sua natureza conceitual complexa, limita a abordagem sobre determinada conjuntura política a ser analisada. Entretanto, existem elementos teóricos que entendemos ser possível mobilizar em favor de um conceito ampliado de ideologia dominante, dentre os quais se destacam os elaborados por Karl Marx, Friedrich Engels e Poulantzas. Dessa forma, o objetivo deste artigo é discutir os referidos elementos teóricos.

Este trabalho, baseado em análise bibliográfica, se estrutura em introdução e conclusão, além de outras duas partes. Inicialmente, discutimos os sentidos atribuídos ao conceito de ideologia por Karl Marx e Friedrich Engels. Em seguida, analisamos seus significados como estrutura regional e como conceito relacional na obra de Nicos Poulantzas.

1 Para uma discussão mais detalhada acerca da influência da noção de Estado ampliado e quanto à compreensão de Althusser sobre os aparelhos do Estado capitalista, ver Almeida (2016).

2 Partindo das elaborações de Marx e Engels, que estabelecem as bases teórico-metodológicas iniciais para o debate sobre o tema, Lênin, Gramsci e outros autores marxistas acrescentam novas interpretações sobre a ideologia nos séculos XIX e XX, mas são Althusser (1982; 1999) e Poulantzas (2015; 2019) que estabelecem de forma mais sistemática a relação entre a ideologia dominante e o Estado capitalista. Vejam-se ainda Sampedro (2010), Motta (2014) e Almeida (2016).

3 A referida obra foi lançada no Brasil pela editora Martins Fontes, em 1977, com o título Poder político e classes sociais. Em 2019, após 51 anos da primeira edição da referida obra na França, a Editora Unicamp publicou uma nova tradução a cargo de Maria Leonor Loureiro, com a revisão técnica de Danilo Martuscelli.

4 Definido em O Estado, o poder, o socialismo, título da obra em língua portuguesa, como uma condensação de relações de forças. 


\section{O CONCEITO DE IDEOLOGIA EM MARX E ENGELS}

Um dos significados mais comuns atribuídos a ideologia diz respeito a uma acepção pejorativa ou negativa — que indicaria um conjunto de ideias falsas —, que remonta à disputa política entre Napoleão Bonaparte e os filósofos do Instituto Nacional da França, os quais ele passou a chamar de "ideólogos" como uma forma de desqualificação de seus ideais republicanos. No campo marxista, entretanto, esse sentido negativo está relacionado à obra de Karl Marx e Friedrich Engels, no livro A ideologia alemã $\tilde{a}^{5}$. Tal significado surge quando da crítica aos filósofos idealistas alemães, os quais, para Marx e Engels, desconsideravam a vida social em detrimento do pensamento, o que comprometia toda a lógica pensada por eles para atingir uma suposta libertação do espírito. Mas o conteúdo dessa obra não se resume a essa crítica. $\mathrm{O}$ filósofo venezuelano Luis José Silva Michelena, mais conhecido como Ludovico Silva, questiona parte das interpretações realizadas sobre $A$ ideologia alemã e observa que a ênfase que se dá à crítica feita por Marx e Engels aos idealistas pode obscurecer outra grande contribuição dessa obra:

Outra grave consequência decorrente da leitura superficial de Marx tem consistido em crer - e fazer crer - que uma obra como A ideologia alemã se esgota na crítica à "ideologia alemã". O manuscrito de Marx e Engels - que por desgraça foi entregue à "crítica destrutiva dos ratos" durante muito tempo - é muito mais que isso: contém, ainda que imperfeitamente, os elementos básicos da teoria geral da ideologia do ponto de vista do materialismo histórico (SILVA, 20I7, p. I78, tradução nossa).

No sentido apontado por Silva, de contribuir para uma teoria da ideologia, devemos atentar para os fundamentos presentes na obra escrita em I845-I846. Se por um lado naquela obra Marx e Engels estabelecem as bases fundamentais para esse estudo, por outro esses fundamentos não tiveram um posterior desenvolvimento por parte dos autores, pelo menos não da forma sistemática como Marx fez em relação à estrutura material de produção da sociedade. Esse exame constitui, entretanto, um importante subsídio para analisar o papel concreto das formações ideológicas e as determinantes da ideologia capitalista. Ao observarmos as relações de produção, por exemplo, constatamos que elas têm como um dos seus pressupostos o isolamento do sujeito enquanto indivíduo, apartado de sua classe e em "concorrência" com seus pares. Essa constatação permite pensarmos o efeito da ideologia jurídica sobre essas relações e, ao mesmo tempo, verificarmos uma de suas principais funções, que, ao cabo, constitui sua particularidade própria na formação social capitalista. Mesmo assim, ao descreverem os elementos fundamentais para uma teoria da ideologia, Marx e Engels deixaram diversos pontos de reflexão em aberto, razão pela qual ainda persistem múltiplos usos e equívocos sobre o termo ideologia (SILVA, 20I7). Ludovico Silva entende

5 A ideologia alemã, obra escrita entre os anos de 1845 e 1846, foi publicada pela primeira vez somente em 1932, pelo Instituto Marx-Engels de Moscou. 
que, a partir de A ideologia alemã e de uma releitura sistemática da obra de Marx e Engels como um todo, é possível estabelecer interpretações complementares do conceito de ideologia, já que, segundo ele, "nem Marx nem Engels cunharam uma noção específica de ideologia, mas isso não nos impede de poder extrair uma caracterização precisa o suficiente a partir dos numerosos textos que ambos os autores dedicaram ao assunto" (SILVA, I978, p. I3, tradução nossa). Essa falta de caracterização ocorreu em razão de seus objetivos de estudo. Em carta escrita a Franz Mehring, em I893, Engels reconhece que não descreveram suficientemente cada conceito utilizado:

Nós colocávamos - e éramos obrigados a colocar - a ênfase principal, antes de mais nada, em derivar dos fatos econômicos fundamentais as ideias políticas, jurídicas e outras noções ideológicas e as ações por elas desencadeadas. Mas o respeito ao conteúdo nos fazia negligenciar a forma, ou seja, o processo de gênese dessas ideias (ENGELS, 1969, p. 408, tradução nossa).

Apesar do que relata Engels, diversos autores reconhecem que ele e Marx representam um marco na utilização do termo (MANNHEIM, I950; LÖWY, I99I; MÉSZÁROS, 20II; ALTHUSSER, I999). Ainda assim, contudo, a afirmação de que seria possível uma determinação precisa da ideologia na obra de Marx não é consenso. Thompson (20II, p. 49) ressalta que é possível uma aproximação dos sentidos utilizados para o termo, mas acredita que "as maneiras precisas como ele [Marx] empregou o conceito de ideologia e as maneiras como lidou com os vários assuntos e os vários pressupostos que estavam ligados a seu uso não são nada claros”. Essa ausência de uma definição particular sobre o conceito em tela na obra de Marx nos obriga a coletar os principais aspectos de suas análises e adequar a análise de cada objeto de estudo concreto.

Diante dessa possibilidade e da riqueza de significados com que se apresenta a ideologia como objeto teórico, uma síntese desses significados na obra de Marx e Engels se apresenta necessária para compreendermos o que posteriormente foi incorporado sobre o tema na obra de autores que os seguiram, como Lênin, Gramsci, Althusser, Poulantzas e Pêcheux. Ainda que conscientes dos possíveis "riscos" de toda espécie de recorte acerca de um conceito, mas também considerando as vantagens desse procedimento, buscamos estabelecer as principais características que assume o termo nos diferentes contextos históricos em que foi utilizado. O objetivo dessa proposta é, ao final, acessarmos alguns pontos importantes que compõem as relações entre a ideologia e o Estado na formação social capitalista em suas derivações simbólicas.

Os significados que assume o termo ideologia nas obras de Marx apresentam variações, mas também certas continuidades, se os interpretarmos conforme as circunstâncias históricas em que foram pensados. Inicialmente, no contexto de combate aos jovens hegelianos, Marx e Engels se dedicaram à crítica do idealismo, entendido por eles como uma forma de pensamento desconectada das condições da realidade material e a serviço dos detentores dos recursos materiais: "as formações nebulosas 
na cabeça dos homens são sublimações necessárias de seu processo de vida material, processo empiricamente constatável e ligado a pressupostos materiais" (MARX; ENGELS, 2007, p. 94). Em contraponto à abstração idealista, entendiam os autores que o pensamento era uma expressão das condições vividas. Em suas palavras:

Não é a consciência que determina a vida, mas a vida que determina a consciência. No primeiro modo de considerar as coisas, parte-se da consciência como do indivíduo vivo; no segundo, que corresponde à vida real, parte-se dos próprios indivíduos reais, vivos, e se considera a consciência como sua consciência (MARX; ENGELS, 2007, p. 94).

Em razão desse enfrentamento do idealismo, Marx e Engels assumiram o sentido pejorativo do termo, mas, diferentemente do que fez Napoleão ${ }^{6}$, atribuíram a ele um referencial teórico e uma argumentação baseada no materialismo. Afirmaram que nenhuma forma ideológica é autônoma, independentemente de como ela se apresenta — religiosa, moral ou metafísica —, isso porque está ligada a pressupostos materiais, as condições impostas pela forma relacional do modo de produção capitalista. Dessa forma, entendiam que as ideias dominantes eram as ideias da classe dominante; a ideologia dominante então era nada mais do que a expressão ideal das relações sociais que a faziam classe dominante. Por essas razões, Marx e Engels entendiam que era a realidade material que formava a consciência, e não o contrário. $\mathrm{O}$ caminho a ser percorrido deveria ser da materialidade às ideias. Dessa forma,

totalmente ao contrário da filosofia alemã, que desce do céu à terra, aqui se eleva da terra ao céu. Quer dizer, não se parte daquilo que os homens dizem, imaginam ou representam, tampouco dos homens pensados, imaginados e representados para, a partir daí, chegar aos homens de carne e osso. Parte-se dos homens realmente ativos e, a partir de seu processo de vida real, expõe-se também o desenvolvimento dos reflexos ideológicos e dos ecos desse processo de vida (MARX; ENGELS, 2007, p. 94).

Para os autores, a própria ideia de autonomia da consciência e, assim, de considerar os indivíduos concretos como produtos das ideias em vez de produtores delas, é uma inversão. Essa idealização da consciência se apresenta, por si só, como resultado de condições e processos históricos particulares, dos quais os homens nem sempre têm consciência (THOMPSON, 20II). Vai nesse sentido um dos trechos mais citados daquela obra:

A consciência [Bewusstsein] não pode jamais ser outra coisa senão o ser consciente [bewusste Sein], e o ser dos homens é o seu processo de vida real. Se, em toda ideologia, os homens e suas relações aparecem de cabeça para baixo

6 A palavra ideologia teria sido criada por Destutt de Tracy, em 1802, na obra Elementos da ideologia, para denominar uma nova ciência interessada na análise sistemática das ideias e sensações. Napoleão Bonaparte (1769) apropriou-se do termo, dando-lhe novo sentido ao relacionar a ideologia a um agrupamento de ideias sem lastro na realidade, a um projeto falso ou mentiroso de sociedade. Para uma revisão histórica detalhada do conceito, ver Konder (2002), Larraín (2008) e Žižek (1996). 
como numa câmara escura, esse fenômeno resulta do seu processo histórico de vida, da mesma forma como a inversão dos objetos na retina resulta de seu processo de vida imediatamente físico (MARX; ENGELS, 2007, p. 94).

A “inversão dos objetos na retina” resulta em um processo de falseamento da realidade e, dessa forma, o processo ideológico leva à falsa consciência, termo que não foi utilizado pelos autores naquela obra, mas pode representar de forma fiel como eles entenderam o efeito da ideologia da época ${ }^{7}$. Esse falseamento, vale lembrar, não foi explorado por eles como uma "mentira". Por meio de uma leitura atenta, verificamos que ideologia no sentido de "falsidade" expressa a inversão, presente na realidade material, de um mundo que se apresenta também dessa forma invertida. Conforme interpretamos a realidade material pelas lentes da ideologia, a primeira passa a ser, assim, simultaneamente prática e representação de si. Por exemplo, ajoelhar-se diante de um sacerdote é, simultaneamente, o ato de ajoelhar-se e o que ele representa. É ação e conteúdo. Então, se compreendermos que a ideologia só existe enquanto prática (ALTHUSSER, 1982) e que a ideologia dominante expressa as relações ideais presentes na sociedade capitalista (MARX; ENGELS, 2007), isso significa que essas relações, a materialidade em si, são por si só uma realidade invertida. Esse aspecto deve ser considerado apenas como um fator, dentre outros que se apresentam a respeito do conceito de ideologia nessa obra. Não há dúvida de que é uma característica fundamental, entretanto não é a única. A esse respeito, Mészáros (20II, p. I42) observa que "as tentativas equivocadamente concebidas de reduzir a ideologia à falsa consciência estão frequentemente associadas a uma visão rígida, fetichista de ciência”. Sendo assim, a variação do conceito de ideologia pode ser melhor compreendida pelo exame da especificidade social e histórica. Quando a ideologia é examinada em suas práticas verificamos que as noções de ideologia e falsa consciência podem ou não coincidir a depender da conjuntura concreta em que são analisadas. Dessa análise, pode-se concluir que se extrai do pensamento uma noção falseada das condições objetivas de classe. Contudo, ainda assim, nesse falseamento, há um lastro de realidade. Larraín (I988, p. I84) afirma que, nesse sentido, o próprio Marx entende que existe uma mediação com substrato na realidade:

A conexão entre "consciência invertida" e "realidade invertida" é mediada por um nível de aparências que é constitutivo da própria realidade. Essa esfera de "formas fenomenais" é constituída pelo funcionamento do mercado e da concorrência nas sociedades capitalistas, e é uma manifestação invertida da esfera da produção, o nível subjacente das "relações reais".

Nesse aspecto, a ideologia não se expressa como um obstáculo à realidade, nem constitui uma simples mentira. Esse fator importa também na obra de Karl Mannheim

7 De fato, a expressão falsa consciência remete à carta de Engels a Franz Mehring, de 1893. Ao buscar esclarecer o aspecto da consciência no processo ideológico, Engels afirmou: "A ideologia é um processo realizado pelo chamado pensador consciente, é verdade, mas com uma falsa consciência. As verdadeiras forças motrizes que o impulsionam permanecem desconhecidas para ele; caso contrário isso não seria um processo ideológico" (1969, p. 408, tradução nossa). 
Ideologia e utopia, de 1950. O autor parte de uma abordagem muito distinta daquela de Marx e Engels acerca da ideologia: quando identifica a "ideologia particular", explica que ela constitui

disfarces mais ou menos conscientes da natureza real de uma situação, cujo verdadeiro reconhecimento contraria os seus interesses. Essas deformações abrangem uma vasta gama de variações - das mentiras conscientes aos disfarces semiconscientes e mesmo inconscientes; das tentativas calculadas para iludir o próximo às formas mais ingênuas de automistificação (MANNHEIM, I950, p. 5I).

Assim, por questão de método, quando nos deparamos com uma das práticas da ideologia - o discurso político, por exemplo — não devemos considerá-la, a princípio, como mentirosa. O sujeito do discurso não está, necessariamente, sempre mentindo, ou pode não ter plena consciência do que diz.

Esses aspectos são favoráveis a uma interpretação mais ampla e, a nosso juízo, necessária da acepção de ideologia presente na obra de I845. A ideologia pode ser definida assim como "uma doutrina teórica e uma atividade que olha erroneamente as ideias como autônomas e eficazes e que não consegue compreender as condições reais e as características da vida sócio-histórica" (THOMPSON, 20II, p. 5I). Assim, mesmo que a ideologia esteja ou possa estar imersa no problema da falsa consciência, ela é a representação das condições materiais que determinam o pensamento e, assim, dizem respeito também a como essa materialidade concreta é interpretada pelo inconsciente. Nesse sentido, além dos fatores materiais que afetam a consciência, "as verdadeiras forças propulsoras" que movem o pensador permanecem ignoradas por ele, pois, de outro modo, "não seria tal processo ideológico" (SILVA, 20I7, p. 197).

Nota-se que $A$ ideologia alemã estabelece alguns aspectos conceituais de relevância para os trabalhos posteriores de Marx e Engels sobre o tema. Isso se constata quando pensamos a ideologia, por exemplo, seu sentido negativo, seu caráter ilusório e sua relação com as condições de produção. Essa conotação negativa permanece na relação que os autores fazem posteriormente da ideologia com as condições econômicas e a classe dominante no prefácio a Contribuição à crítica da economia política, de i859. Nesse texto, Marx afirma que as relações de produção são o principal vínculo entre os indivíduos na formação social capitalista, e com isso determinam o ser social e suas práticas. Antes, na obra de I845, os autores já asseguravam que a ideologia na formação social deve ser entendida tomando-se por base a força material dominante na sociedade:

As ideias da classe dominante são, em cada época, as ideias dominantes, isto é, a classe que é a força material dominante da sociedade é, ao mesmo tempo, sua força espiritual dominante. A classe que tem à sua disposição os meios da produção material dispõe também dos meios da produção espiritual, de modo que a ela estão submetidos aproximadamente ao mesmo tempo os pensamentos da-

8 Essa distinção se opõe a outra espécie de ideologia, aquela que se refere à ideologia de uma época, de um grupo histórico concreto, uma classe específica (MANNHEIM, 1950). 
queles aos quais faltam os meios da produção espiritual. As ideias dominantes não são nada mais do que a expressão ideal das relações materiais dominantes, são as relações materiais dominantes apreendidas como ideias; portanto, são a expressão das relações que fazem de uma classe a classe dominante, são as ideias de sua dominação (MARX; ENGELS, 2007, p. 47, grifos nossos).

Ao entenderem que a ideologia resulta de uma relação de dominação da classe burguesa sobre a classe operária, e que por intermédio dela se faz possível a universalização de interesses particulares, os autores lhe reforçam o sentido pejorativo, cunhado por Napoleão, mas dessa vez relacionam expressamente a dominação ideológica à dominação material da burguesia. Dessa concepção, se percebe o vínculo da ideologia com as relações capitalistas, preservadas e transformadas pela imposição de uma visão ilusória dessas relações. $\mathrm{O}$ emprego pejorativo desse termo pelos autores denuncia a ilusão e indica uma consciência deformada, desconectada da realidade (LÖWY, I99I). A expressão falsa consciência, ainda que não tenha sido utilizada pelos autores na obra de I845, descreve adequadamente o pensamento deles acerca do termo. Apesar disso, o sentido pejorativo de ideologia como "falsificação da realidade", ou mesmo como "obstáculo a uma consciência real”, predominou nas interpretações de tradição marxista, fato que se modificaria apenas a partir da teoria leninista sobre a organização proletária.

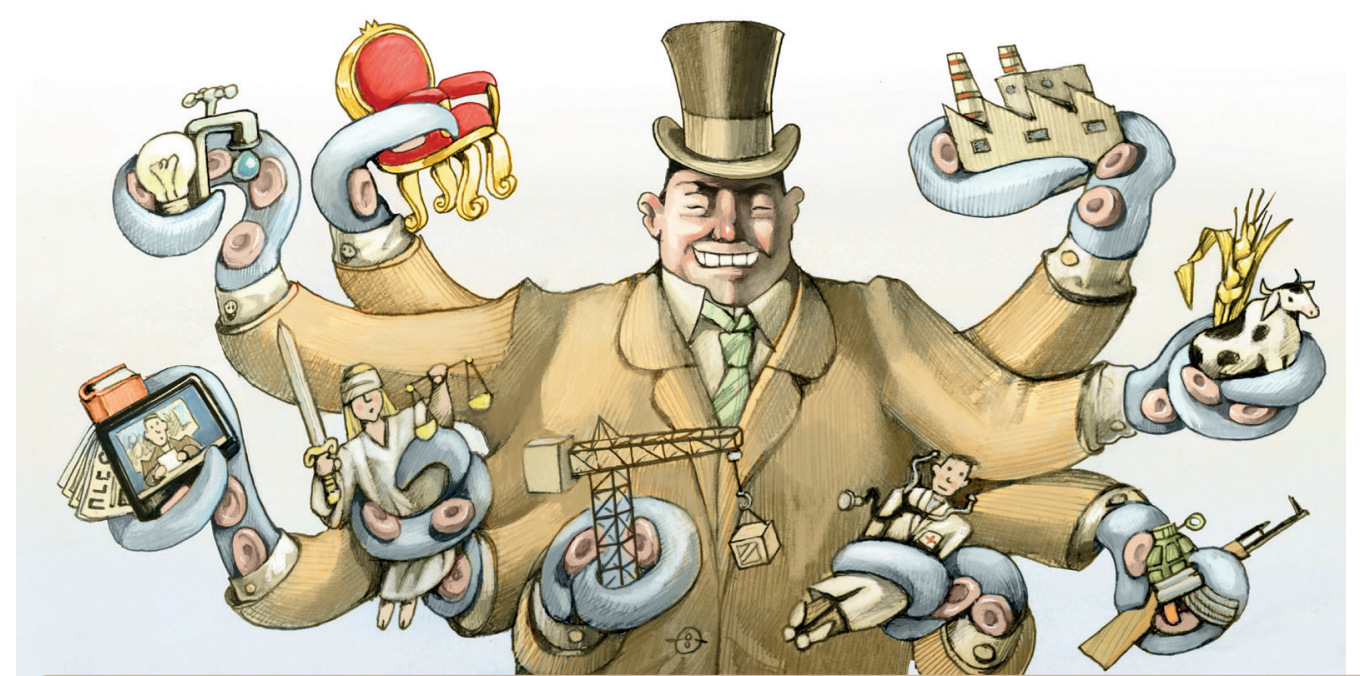

A interpelação a que Althusser se refere, no processo discursivo, cria essa evidência do sentido e apaga seu caráter de classe, criando a ilusão de que o sentido do discurso é algo dado e não algo relacionado à estrutura social 
A ideologia, em um segundo momento (1859) da obra de Marx e Engels, pode ser entendida como um sistema de ideias que expressa os interesses da classe dominante por meio de uma representação ilusória das relações econômicas ante as classes populares. Com isso, a consciência do indivíduo e, acrescentamos, suas práticas, não são vistas como autônomas. Ao contrário, devem ser examinadas segundo as condicionantes do modo de produção. Em razão disso, as representações que os indivíduos fazem de si e de suas práticas sociais assumem uma dimensão ideológica que dá sentido à realidade e coesão à forma do Estado (MARX; ENGELS, 2007; ALTHUSSER, 1982; POULANTZAS, 2015; 2019). Esse aspecto é especialmente relevante, pois, nessa lógica, as formas ideológicas de consciência devem ser explicadas pela análise das condições econômicas de produção nos processos de transformação social. É nesse sentido que a análise da ideologia de Estado se reporta também aos aspectos da reconfiguração da luta de classes e dos interesses em conflito.

Os elementos apontados neste último sentido ligam a produção material à produção das ideias, e isso nos traz uma definição de ideologia que, de certa mentira, supera o entendimento acerca da falsa consciência, sem, contudo, abandoná-lo. Ocorre nesse aspecto uma reformulação do conceito, que se apresenta de forma mais clara em A ideologia alemã e no prefácio a Contribuição à crítica da economia política (I859), mas incorpora-se aos escritos de Marx e Engels de forma mais periférica e, até certo ponto, subliminar, a partir do livro O I8 de brumário de Luís Bonaparte, a qual podemos designar como concepção "latente" sobre a ideologia. Esse termo é empregado, como se refere Thompson (20II), para designar os fenômenos que constam da obra de Marx, aos quais o autor não se reporta diretamente como fenômenos ideológicos:

Os fenômenos apresentados como sendo essa concepção latente de ideologia não são meros epifenômenos das condições econômicas e das relações de classe; ao contrário, eles são construções simbólicas que têm certo grau de autonomia e eficácia. Eles se constituem em símbolos e slogans, costumes e tradições que mobilizam as pessoas ou prendem-nas, empurram-nas para a frente ou constrangem-nas, de tal modo que não podemos pensar essas construções simbólicas unicamente como determinadas, ou totalmente explicadas, em termos de condições econômicas de produção (THOMPSON, 20II, p. 58, grifos nossos).

A ideologia apresentada sob forma de construções simbólicas é frequente na prática discursiva, e, por essa razão, tal interpretação deve ser considerada como parte da análise de processos de mudança ou de conservação social, como entendemos que Marx faz nessa obra. Nos contextos em que aparece, essa concepção não é descrita pelo termo ideologia. Em vez disso, afirma Thompson (20II, p. 56), ele utiliza "ilusões, ideias fixas, espíritos ou fantasmas [...,] que andam no meio do povo e procuram despertar suas superstições".

Podemos encontrar exemplos disso em diversas passagens, nas quais, vale ressaltar, Marx se refere à disputa partidária da época e aos interesses reais que se apresentavam se examinássemos além da aparência: 
Um exame mais detido da situação e dos partidos [...] faz desaparecer essa aparência superficial, que mascara a luta de classes e a fisionomia peculiar desse período. [...]

E, assim como na vida privada se costuma diferenciar entre o que uma pessoa pensa e diz de si mesma e o que ela realmente é e faz, nas lutas históricas devem-se diferenciar tanto mais as fraseologias e ilusões nutridas pelos partidos do seu verdadeiro organismo e dos seus reais interesses, devem-se diferenciar as suas concepções da sua realidade. Na República, orleanistas e legitimistas estavam lado a lado com as mesmas pretensões (MARX, 20II, p. 59-6I, grifos nossos).

Em outro trecho célebre o autor se refere à "reedição do I8 de brumário9":

A tradição de todas as gerações passadas é como um pesadelo que comprime o cérebro dos vivos. E justamente quando parecem estar empenhados em transformar a si mesmos e às coisas, em criar algo nunca antes visto, exatamente nessas épocas de crise revolucionária, eles conjuram temerosamente a ajuda dos espíritos do passado, tomam emprestados os seus nomes (MARX, 20II, p. 25).

No contexto apresentado por Marx sobre a França de Luís Bonaparte, a ideologia se apresentava como uma forma simbólica de mobilização social, o que, naquele caso, resultou na mobilização para conservação. Isso nos mostra como essas formas simbólicas são também um elemento transmitido pelo passado a ponto de constituírem os costumes, novas tradições, que, no plano da formação social, constituem práticas ideológicas. No plano das transformações sociais, a ideologia incide na realidade como práticas que, dialeticamente, atuam como constituintes e reflexos das relações políticas e econômicas. Nesse sentido, Mészáros afirma que uma das principais características da ideologia é ser:

A consciência prática inevitável das sociedades de classe, preocupada com a articulação e afirmação dos conjuntos rivais de valores e estratégias [...] pelo propósito vital de levar até o fim o conflito fundamental na arena social, posto que os conjuntos rivais de valores são inseparáveis de alternativas hegemônicas objetivamente identificáveis da situação histórica dada (MÉSZÁROS, 2OII, p. I44-I45, grifos originais).

De acordo com essa lógica, os aspectos da "concepção latente" de ideologia apresentam, a nosso juízo, uma importante contribuição no exame dos processos de transformação ou conservação de poder. O "aspecto estratégico" da noção da ideologia também pode ser observado na formulação desse conceito por parte de Lênin.

9 No dia 18 de brumário (9 de novembro) de 1799, Napoleão Bonaparte derrubou, mediante um golpe de Estado, o Diretório francês, tornando-se ditador com o título de primeiro-cônsul. Com a "reedição do 18 de brumário", Marx se refere ao golpe de Estado desferido por Luís Bonaparte no dia 2 de dezembro de 1851. 


\section{A principal contribuição que Lênin traz com a sua elaboração teórica sobre a ideologia, em termos teóricos conceituais, é que ele "retira" parte da conotação negativa atribuída ao termo em $A$ ideologia alemã}

Vale lembrar que Lênin não teve acesso à obra A ideologia alemã, escrita entre $\mathrm{I} 845 \mathrm{e}$ I846, mas publicada apenas em I932, oito anos após seu falecimento. Assim, sua concepção de ideologia não continha uma valoração negativa da ideologia, como "falsa consciência", tal qual formulada na obra citada.

Lênin não se dedicou à sistematização de um conceito acabado de ideologia, pois sua intenção ao utilizar o termo estava ligada aos aspectos práticos da organização do partido e da "luta ideológica". Por essa razão, em muitos de seus escritos, os conceitos aparecem de forma simplificada, dirigidos para a ação política da classe operária. Ainda assim, é possível, em seus textos, ter uma noção clara do que pensava sobre o tema. Sua definição de ideologia aponta para "um conjunto de crenças que reúne e inspira um grupo ou classe específicos a perseguir interesses políticos considerados desejáveis. E então, com frequência, sinônimo da acepção positiva de consciência de classe" (EAGLETON, 20I9, p. 50). Essa noção positiva da ideologia só é possível pela oposição que propõe à ideologia burguesa. Entretanto, a ênfase é na possibilidade de emancipação proletária mediante uma estratégia da classe trabalhadora e não no caráter negativo ou pejorativo da formação ideológica burguesa. Ao apontar para a necessidade de uma "luta ideológica", o autor deixa clara a dicotomia entre a burguesia e o proletariado, apontando para as consequências da existência de "ideologias intermediárias":

O problema põe-se exclusivamente assim: ideologia burguesa ou ideologia socialista. Não há meio-termo (pois a humanidade não elaborou uma "terceira" ideologia; e, além disso, em uma sociedade dilacerada pelos antagonismos de classe, não seria possível existir uma ideologia à margem ou acima dessas classes). Por isso, toda diminuição da ideologia socialista, todo distanciamento dela implica o fortalecimento da ideologia burguesa. Fala-se de espontaneidade. Mas o desenvolvimento espontâneo do movimento operário resulta justamente na subordinação à ideologia burguesa, efetua-se justamente segundo o programa do "credo", pois o movimento operário espontâneo é o sindicalismo [...; ] ora, o sindicalismo é justamente a escravidão ideológica dos operários pela burguesia (LÊNIN, 1976, p.39I, tradução nossa). 
Com essa referência, não queremos afirmar, de forma simplista, que o autor não compreendia as nuanças dos aspectos da ideologia no campo teórico-analítico. Lênin, que tinha claramente uma visão dialética dos processos sociais, compreendia que não havia apenas duas ideologias. Fica claro, nessa passagem, que Lênin estava preocupado com o "espontaneísmo" no campo ideológico, que tinha como consequência o "sindicalismo" na luta operária, o que todos deveriam combater também por meio da ideologia própria. A esse respeito vale lembrar que, em um contexto diferente daquele em que viveu Lênin, o Estado capitalista no Ocidente apresenta diversos subconjuntos ideológicos, os quais são passíveis de incorporação na ideologia dominante. É justamente essa dicotomia que se vê desfeita - em favor da classe dominante - na análise da ideologia do Estado capitalista. A esse ponto retornaremos nas páginas seguintes. Quanto ao caráter dual da "luta ideológica" e a oposição valorativa (negativo-positivo), se fundamenta na existência do que Lênin (I976) designou como uma ideologia transformadora e socialista. Nesse sentido, a ideologia socialista (sentido positivo) estaria em oposição à burguesa (sentido negativo), e o conflito ideológico deveria ser incorporado à estratégia proletária. Uma utilização similar também faz Lukács do termo ideologia. Sua reflexão, nos anos 1920, acerca dos problemas e tarefas que os movimentos da classe trabalhadora enfrentavam, menciona a necessidade da consolidação de uma "ideologia do proletariado" para os destinos da revolução. Nossa intenção em pontuar esses aspectos não é, contudo, adentrar no debate acerca da organização da classe proletária da época. O que pretendemos com isso é extrair algumas das características da formulação de Lênin acerca da ideologia e, principalmente, o fator de renovação que traz ao conceito.

A principal contribuição que Lênin traz com a sua elaboração teórica sobre a ideologia, em termos teóricos conceituais, é que ele "retira" parte da conotação negativa atribuída ao termo em A ideologia alemã. Isso é possível notar mediante uma comparação retrospectiva que fazemos agora, e que o próprio Lênin não fez, por desconhecer a obra publicada em I932. Nesse sentido, podemos dizer que ele dá "novo sentido" ao termo, ao associá-lo a uma estratégia da classe trabalhadora, que por si só era considerada positiva, já que se confundia com uma necessária "consciência de classe" (EAGLETON, 20I9). Aqui a acepção negativa do termo é minimizada, já que é perceptível somente se a pensarmos em oposição à ideologia burguesa, entendida como um obstáculo à emancipação.

Outra consequência desse novo sentido atribuído ao conceito por Lênin e, também, por Lukács é o que Thompson (20II) chamou de "neutralização implícita do conceito de ideologia”. Para o autor, Lênin e Lukács, ao adaptarem o conceito de ideologia de Marx de I859, generalizaram essa concepção de tal modo que ideologia passou a se referir às ideias que expressam e promovem os respectivos interesses das classes fundamentais. Com essa definição, os autores eliminaram o "aspecto assimétrico" da acepção de Marx, de I859, e com isso alargaram o conceito, de forma que ideologia teria perdido o sentido negativo, bem como sua referência às ideias dominantes. $\mathrm{A}$ 
essa neutralização, mais tarde, Poulantzas (20I5; 20I9) se insurge por meio das críticas acerca da corrente "historicista" de marxistas, conforme veremos na próxima subseção. Isso porque, se há algo recorrente na concepção de ideologia em Marx e Engels, é o fato de ela expressar os interesses da classe dominante e não ideais que expressam os interesses das classes como tais. Nesse sentido,

Marx nunca falou da "ideologia socialista" ou da "ideologia proletária", e ele nunca caracterizou o materialismo histórico como a "ideologia do proletariado" [...;] para Marx, era o reino das doutrinas abstratas e das ideias ilusórias que poderia, talvez, confundir o proletariado (THOMPSON, 2OII, p. 86).

Dessa forma, a ideologia, para Marx e Engels, não era um instrumento de luta da classe operária, mas um obstáculo ao qual se teria de superar para uma real emancipação.

Essas questões não se apresentam para nós apenas como uma crítica à formulação de Lênin, mas são relevantes para nosso trabalho justamente porque estabelecem uma diferença interpretativa acerca da ideologia, que influencia diretamente no que entendemos por ideologia do Estado. Podemos fazer a seguinte síntese: I) se entendemos a ideologia como falsa consciência apenas, o discurso na cena política sempre será um dispositivo que leva as classes subalternas ao erro, a uma percepção distorcida da realidade que vivem e, com isso, a uma falsa percepção também do Estado e da política; 2) se entendemos a ideologia como a expressão de um conjunto de crenças e valores de uma classe específica, o discurso na cena política sempre será e expressará a ideologia dessa classe de forma "pura", uma ideologia de classe linear. Ou seja, esses aspectos do conceito de ideologia, quando examinados em uma formação social concreta, constituem uma determinada compreensão da conjuntura da luta de classes. Esse conhecimento da situação concreta acerca das relações ideológicas determinará não apenas um tipo de análise e exposição teórica, mas também uma estratégia política para a reprodução ou transformação social. Essa é também a consequência apontada por Poulantzas ao problematizar o conceito de ideologia sob o registro do que chamou de ideologia geral e ideologias particulares do Estado. Antes de tratarmos da ideologia enquanto prática social, abordaremos os sentidos do conceito de ideologia na obra de Poulantzas.

\section{AS CONTRIBUIÇÕES DE NICOS POULANTZAS PARA UMA COMPREENSÃO AMPLIADA DA IDEOLOGIA}

É em sua obra Poder político e classes sociais que o autor mais se detém no conceito de ideologia, na forma da ideologia jurídico-política. Nesse momento, Poulantzas estabelece uma relação fundamental da ideologia com o político e o modo de produção, especialmente no que diz respeito à função de coesão da formação social capitalista. A ideologia é vista inicialmente como uma estrutura do modo de produ- 
ção ${ }^{10}$, e a ideologia jurídico-política, como uma subdivisão específica, que se apresenta ao lado das demais regiões ideológicas (moral, religiosa, filosófica, econômica, estética etc.) e que assume papel dominante nas formações sociais capitalistas. Dessa forma, se apresenta como uma dimensão predominantemente político-econômica, por sua expressão estrutural-regional. A abordagem da ideologia com ênfase na dimensão político-econômica favorece nossa análise da prática ideológica, como a do discurso político. Favorece a análise por compreender o exame da ideologia em relação ao político, entretanto nos lança ao desafio de operacionalizar alternativas para melhor identificar e compreendê-la na prática social em uma conjuntura de luta política específica.

Para Poulantzas (2019), a ideologia do Estado capitalista consistiria em uma ideologia geral de Estado e em diversas ideologias particulares. Uma dessas regiões é a ideologia jurídico-política (o direito), que se apresenta de modo dominante na formação social capitalista. Essa dominância" ${ }^{\text {II }}$ refere a um fenômeno que ocorre especificamente na formação social capitalista, de forma a criar os efeitos específicos - efeito de isolamento (o processo de individualização-isolamento dos agentes da produção) e efeito de unidade (unificação virtual desses mesmos indivíduos no burocratismo) - que ocultam ou dissimulam os fundamentos das relações de classe presentes na formação social capitalista. No modo de produção capitalista, "a ideologia é mais bem colocada para ocultar o índice real de determinação e de dominância da estrutura [...] [e] também a mais bem colocada para cimentar a coesão das relações sociais, reconstituindo a unidade dessa formação em um plano imaginário" (POULANTZAS, 2019, p. 218). Dessa forma, para o autor grego, uma das regularidades que se apresenta na prática das ideologias capitalistas é a ocultação, a dissimulação, a inversão das relações reais de classe, que ocorre no plano imaginário dos agentes.

Além disso, há também um segundo aspecto determinante do conceito de ideologia que se extrai da obra poulantziana: a ideologia se apresenta, a exemplo do Estado e do capital, como um fenômeno relacional na formação social capitalista. Nesse sentido, primeiramente, mesmo que as ideologias se constituam, em parte, em um conjunto de valores ${ }^{12}$, elas não formam qualquer espécie de "consciência" específica, ou "visão de mundo" particular, homogênea, de uma classe. Ao se referir à ideologia dominante em uma formação social concreta, Poulantzas a identifica não como uma ideologia apenas de uma classe, mas também como a ideologia que reflete as

10 A ideologia como um nível estrutural do modo de produção também foi abordada por Althusser, em duas obras anteriores ao livro Poder político e classes sociais. Conforme nos lembra Almeida (2016, p. 75-76), "tanto em Pour Marx como em Lire Le Capital, apesar de a centralidade do foco incidir, no que se refere ao nosso tema, sobre o papel de obstáculo epistemológico da ideologia, esta é também abordada como um nível estrutural de um modo de produção".

11 Lembramos que Poulantzas (2019) entende que a dominância de uma ideologia particular ocorre na formação social quando esta cumpre com a função de viabilizar a exploração em determinado modo de produção, seja pela ocultação, dissimulação ou legitimação das relações sociais.

12 A expressão conjunto de valores aqui pode ser entendida como parte dos "fatores objetivos da estrutura" (POULANTZAS, 1980, p. 49). É, por essa razão, constituinte da prática da ideologia no âmbito da sociedade. 
relações específicas entre a classe dominante e a classe dominada:

Ora, de fato, a ideologia dominante não reflete simplesmente as condições de vida da classe dominante, sujeito "puro e simples", mas também a relação política concreta, em uma formação social, entre as classes dominantes e as classes dominadas. Ela está muitas vezes frequentemente impregnada de elementos decorrentes do "modo de vida" de outras classes e frações que não a classe ou fração dominante (POULANTZAS, 2019, p. 206).

A ideologia dominante, nesse sentido, não é apenas a expressão do modo como a classe ou a fração dominante do bloco no poder vive suas condições de existência, mas é reflexo também do modo como a classe subalterna as vive em relação à institucionalidade do Estado e ao modo de produção. Na formação social capitalista, as classes fundamentais são interdependentes quanto às suas condições de existência, pois, assim como não pode haver classe burguesa sem o proletariado, ou vice-versa, a ideologia típica dessas classes é constituída até as raízes pela ideologia da classe antagonista (EAGLETON, 20I9; POULANTZAS, 20I9). As ideologias dominantes devem se moldar às experiências vividas pelas classes subalternas, bem como a ideologia das classes populares, em sua relação com a ideologia das classes dominantes, deve absorver suas práticas fundamentais. Poulantzas (20I9, p. 206) exemplifica essa integração entre a ideologia dominante e alguns elementos da ideologia das classes subalternas: "é o caso, clássico, por exemplo, de recepção, na ideologia burguesa das formações sociais capitalistas, de 'elementos' da ideologia pequeno-burguesa (o 'jacobismo', e o seu sucessor, o 'radicalismo')".

A unidade de uma formação social, para Poulantzas, é determinada por uma questão estrutural, um efeito das superposições de vários "níveis" ou "regiões" da vida social, determinados, em última instância, pelos limites estabelecidos pelo modo de produção. Esse aspecto fundamental - a estrutura - reforça a impossibilidade de conciliação do conceito de ideologia posto pelo autor com aquela interpretação "historicista" das ideologias ${ }^{13}$, segundo a qual a ideologia teria uma natureza homogênea e coesa, e as classes teriam a possibilidade de dispor delas como instrumento puro de dominação de classe.

Esse debate, ainda que cheio de nuanças que não abordaremos neste trabalho, reflete uma crítica fundada no argumento estruturalista - apresentado por Poulantzas - de negação de ideologias "puras", de uma constituição de classes sociais com uma visão de mundo mais ou menos homogênea, e está relacionado, sobretudo, à possibilidade de constituição hegemônica pela imposição da "visão de mundo" de uma classe específica. Essa visão sobre as ideologias supõe uma relação excessivamente orgânica e interna entre um "sujeito de classe" e sua "visão de mundo" (EA-

13 A crítica ao historicismo se dirige, especialmente, a autores como Sartre, Lukács, Korsch e Gramsci, e pode ser encontrada na obra Ler o Capital, especialmente no título V, "O Marxismo não é um Historicismo", de autoria de Althusser (1980). Sob o paradigma althusseriano, Poulantzas (2019) retoma essa crítica na sua obra magna. Tal retomada, especialmente em relação à ideologia, pode ser constatada na Parte III, título II, "O Estado capitalista e as ideologias". 
GLETON, 20I9, p. II7). A oposição a essa visão por parte de Poulantzas também é fundamento de Louis Althusser, que trabalha a ideologia não no plano do consciente, mas sim no plano imaginário das relações sociais (MOTTA, 20I0). A ideologia, para o autor argelino, é um sistema de representações (não apenas ideias), imagens e conceitos que se impõem aos sujeitos por meio de estruturas e que se materializam por meio de práticas. Nesse sentido, não haveria uma consciência "falsa" ou "verdadeira" sobre as relações sociais, mas apenas uma apreensão imaginária por parte dos sujeitos sobre as relações vividas no mundo ${ }^{14}$.

A visão historicista reduziria a ideologia à organização política de classe, e "essa organização política, à constituição de uma concepção do mundo própria, que a erigiria em classe para si, sujeito da história - identificação da consciência política de classe com a função detida pela concepção do mundo" (POULANTZAS, 20I9, p. 206). A ideologia dominante, entretanto, não é algo exterior às classes, e as concepções de mundo não estão apartadas do processo imaginário dos sujeitos. Nesse sentido, a classe dominante não teria como dispor da ideologia (conjunto de valores e representações) como um instrumento a priori, já que esta constitui para ela, bem como para a classe subalterna, algo que lhe é intrínseco. Em outras palavras, a burguesia vive a ideologia dominante, já que realmente acredita nos valores que fundamentam as relações capitalistas (a liberdade, a igualdade formal, a universalidade do Estado etc.). A classe dominante realmente experimenta na sua ideologia essa relação imaginária com as suas condições reais de existência. Ao expressarem essas relações "imaginárias", os sujeitos subjugam suas relações reais, levando a uma sobredeterminação do imaginário pelo real (ALTHUSSER, 20I5) ${ }^{15}$.

Isso não significa, contudo, que não haveria uma ideologia de classe, pois toda ideologia capitalista corresponde a uma ideologia de classe, ou, ainda, a uma situação específica da conjuntura das classes. O argumento que nos trazem Poulantzas e Althusser é o de que essa ideologia — dominante - é composta por diversas outras, correspondentes a outras classes e suas frações. Em outra passagem, o autor sintetiza a problemática que se estabelece entre consciência de classe e ideologia dominante:

14 Em Ideologia e aparelhos ideológicos do Estado, Althusser (1982, p. 82) afirma que "na ideologia, o que é representado não é o sistema das relações reais que governam a existência de indivíduos, mas as relações imaginárias desses indivíduos com as relações reais em que vivem". Nesse sentido, o que a ideologia representa "é a relação imaginária dos indivíduos com as suas condições reais de existência" (ALTHUSSER, 1982, p. 77).

15 autor também afirma que essa sobredeterminação, que se apresenta pelo acúmulo de contradições originadas das diversas instâncias, pode ser reversa. Tal sobredeterminação reversa remete ao momento em que a ideologia reforça ou modifica a relação dos homens com suas condições de existência, ou seja, quando há sobredeterminação do imaginário pelo real (ALTHUSSER, 2015). Essa modificação é possível justamente porque a ideologia, para Althusser, não representa apenas o falseamento da realidade ou mesmo uma mentira. Ainda que essas relações sejam imaginárias, o são no sentido em que não correspondem à realidade tal qual se apresenta, pois a refletem de forma distorcida; são, assim, também "relações imaginadas", representações. Tal representação dessas relações vividas constitui uma ilusão que se sobrepõe à realidade material. Esse imaginário faz alusão às condições de realidade e, sendo assim, "basta 'interpretá-las' para reencontrar, sob sua representação imaginária do mundo, a própria realidade desse mundo (ideologia = ilusão/alusão)" (ALTHUSSER, 1982, p. 78). 
A estrutura - a unidade - da ideologia dominante não pode ser decifrada a partir das suas relações com uma consciência de classe-concepção do mundo, em um compartimento estanque, mas a partir da unidade do campo da luta de classes, ou seja, a partir da relação concreta das diversas classes em luta no interior da qual funciona a dominação de classe (POULANTZAS, 20I9, p. 213, grifos originais).

A interpretação historicista sobre a ideologia resulta, segundo o autor grego, em diversos equívocos interpretativos em relação ao processo de luta de classe ${ }^{16}$, mas seu déficit analítico está em retirar qualquer autonomia da instância ideológica. Particularmente, essa concepção prejudica a identificação da relação concreta entre ideologia dominante e classe ou fração dominante em uma situação historicamente determinada. Na prática, impossibilita a distinção entre hegemonia política e hegemonia ideológica, em suas defasagens em relação à luta de classes em uma conjuntura concreta. Se seguirmos aquela interpretação, sempre coincidiria sob a mesma fração de classe a hegemonia no campo político e no ideológico, ou seja, não haveria defasagens entre os tipos de dominação. Essa visão simplificada do que é a ideologia dominante prejudica a análise da situação histórica concreta e, sendo assim, da estratégia da classe trabalhadora em sua intervenção para a transformação política. Assim, o que é importante destacar é que Poulantzas, ao fazer essa crítica - à qual aderimos — visa à análise da conjuntura. Nesse caso, busca-se a análise das relações ideológicas de modo específico, em maior detalhamento. Ou seja, se pensarmos o modo como se constitui a ideologia dominante, perceberemos que, grosso modo, ela expressará os interesses gerais da burguesia — ampliação do capital e reprodução das relações capitalistas. Já em outra camada mais profunda de análise - em uma conjuntura concreta - , notaremos que elementos da ideologia da classe dominada são incorporados para atender a parte de seus interesses. Estabelecer essa particularidade, portanto, responde à necessidade de maior aprofundamento no exame das relações ideológicas. Dessa forma, nossa leitura tanto sobre as classes sociais quanto sobre as ideologias não poderia, portanto, ser tomada conforme uma visão "historicista" de reduzir as ideologias apenas à expressão "pura" do modo de vida de uma classe.

Seguindo essa característica - de fusão das ideologias - , entendemos que outro aspecto pode ser acrescentado. Com base em uma interpretação extensiva dessa fusão, podemos também dizer que as ideologias que não são dominantes na formação social — as ideologias sobredeterminadas — podem também compor a ideologia dominante. Isso porque nem mesmo o modo de produção, na análise da formação social concreta, se apresenta de um modo "puro". Sabemos que, no exame do modo de produção capitalista, as classes que se apresentam como elementares são a burguesia e o proletariado. A formação social consiste, entretanto, em uma sobreposição de vários modos de produção não dominantes que apresentam, por sua vez, diversas classes ou frações de classe - sobredeterminadas - correspondentes.

16 Ver detalhes em Poulantzas (2019, p. 199-212). 
Nessa lógica, as classes sociais não se apresentam de forma homogênea no exame da formação social capitalista. Como consequência, as ideologias também não poderiam apresentar tal homogeneidade. A característica relacional da ideologia capitalista diz respeito ao nível das práticas da formação social em suas sobredeterminações. Dessa forma, estas geram efeitos sobre a ideologia dominante, já que ocorre a inclusão de diversas formações ideológicas que não das classes fundamentais, mas também daquelas classes oriundas dos modos de produção não dominantes.

Os aspectos levantados sobre a ideologia em Poulantzas nos apontam, até aqui, pelo menos duas características importantes para pensarmos a ideologia de Estado. Por um lado, a característica relacional da ideologia, e, por outro, a possibilidade de sua instrumentalização pela dissimulação, ocultação ou inversão das condições materiais. A primeira diz respeito aos valores e práticas que constituem a ideologia, já a segunda se refere à possibilidade "instrumental" da ideologia para a dominação de classe. Nesse sentido, mesmo que o autor entenda a ideologia capitalista por uma perspectiva relacional, ainda persiste a ideia de que ela possibilita a distorção, a dissimulação das relações de classe, que, dessa forma, atribuem sentido às práticas de dominação de classe. Ao tratar da ideologia dominante, particularmente no caso da junção entre a ideologia geral e a particular (a ideologia jurídica), o intelectual indica essa característica de ocultação:

Um dos caracteres particulares da ideologia burguesa dominante consiste no fato de que ela esconde de uma maneira absolutamente específica a exploração de classe, na medida em que todo traço da dominação de classe está sistematicamente ausente de sua linguagem própria. É verdade que, por seu próprio estatuto, nenhuma ideologia se apresenta como ideologia de dominação de classe (POULANTZAS, 2019, p. 217-218, negritos nossos).

Ainda que Poulantzas entenda que a ideologia tenha essa possibilidade instrumental de classe, há uma distinção importante em relação à teoria marxista clássica da ideologia. Da mesma forma que para Althusser, para Poulantzas a ocultação ou inversão imaginária das relações de classe não parte do pressuposto da existência de uma consciência de classe. Nesse sentido, essa característica da ideologia resulta da sua própria função na formação social capitalista, determinada em "última instância” pelo econômico, que indica, pela própria natureza pela qual se expressa o modo de produção, sua função de inversão imaginária das condições materiais.

Em O Estado, o poder, o socialismo, Poulantzas retoma a questão da ideologia como ocultação-inversão quando trata do problema da ação do Estado por meio do binômio repressão-ideologia para definir o domínio do poder sob as massas. Em uma crítica à distinção feita por Althusser entre aparelhos repressivos e ideológicos do Estado, Poulantzas assegura que as ações do Estado não funcionam apenas de forma negativa (repressão-ocultação), como presume aquela separação, pois essa lógica "supõe que a eficácia do Estado esteja no que proíbe, exclui, impede de fazer, ou, então, no que engana, mente, oculta ou faz crer" (POULANTZAS, 20I5, p. 28, grifos nossos); diferentemente 


\section{Quanto à ação do Estado em favor da ideologia} dominante, não se deve supor, portanto, que ela se dê apenas por meio da ocultação-inversão do imaginário das massas, mas, suplementarmente, que ocorra também em sentido positivo, criando condições objetivas para a adesão das classes populares. Acreditar que o Estado só age pela produção de uma ideologia que levaria à "consciência errada" é insuficiente para entendermos a ideologia dominante

dessa noção, entende o autor que "o Estado também age de maneira positiva, cria, transforma, realiza" (POULANTZAS, 2015, p. 29).

Particularmente quanto à ação do Estado em favor da ideologia dominante, não se deve supor, portanto, que ela se dê apenas por meio da ocultação-inversão do imaginário das massas, mas, suplementarmente, que ocorra também em sentido positivo, criando condições objetivas para a adesão das classes populares. Acreditar que o Estado só age pela produção de uma ideologia que levaria à "consciência errada" é insuficiente para entendermos a ideologia dominante, o Estado e as relações da classe dominante com as classes populares. Porque "a relação das massas com o poder e o Estado, no que se chama especialmente de consenso, possui sempre um substrato material" (POULANTZAS, 2015, p. 28).

Essa atuação positiva ocorre, entre outros fatores, porque o Estado, trabalhando em favor da hegemonia de classe, atua no campo dos compromissos instáveis que configuram as relações entre as classes dominantes e as dominadas. Essa relação entre a ideologia e as massas implica, invariavelmente, a necessidade do Estado de tomar medidas positivas em relação às classes populares (medidas econômicas de inclusão e de melhoria de vida). Interpretar a ideologia do Estado exclusivamente por conta de sua ação de "encobrimento" nos leva a uma conclusão precária sobre as razões do consentimento: seu exame estaria baseado no campo da ilusão ideológica das massas. Nesse ponto, Poulantzas difere de Althusser, que atribuía à ideologia de Estado uma função claramente mistificadora, composta pelo reagrupamento de

um certo número de temas importantes, extraídos dos diferentes domínios da ideologia (religiosa, jurídica, moral, política etc.), em um sistema que resume os "valores" essenciais de que tem necessidade a dominação das 
classes que detêm o poder de Estado para "levar na conversa" os explorados e os agentes da exploração e da repressão, assim como os agentes da ideologização, portanto, para garantir a reprodução das relações de produção (ALTHUSSER, I999, p. I62).

Analisar essa ideologia com base apenas em sua função mistificadora diante das classes subalternas seria, com as devidas adaptações, transportar a lógica da ideologia como representação da falsa consciência e, portanto, do próprio discurso político, como um artifício de indução a erros, e supô-la também como um discurso ideológico apenas no sentido mistificador do termo. Por essa lógica, outras consequências surgem. Porém, a conclusão imediata sobre a estratégia de emancipação subalterna é que dependeria de uma constante luta pela "ilustração das massas" por parte dos revolucionários, sendo que o antagonismo discursivo-ideológico ficaria restrito à mistificação da ideologia burguesa e à enganação das massas. Não se trata, entretanto, de negar o caráter mistificador das ideologias. Como mencionado noutros lugares deste artigo, a ideologia jurídico-política, por exemplo, atua também nesse sentido:

Que o aspecto ideológico-engodo esteja sempre presente, isso não altera o fato de que o Estado também age pela produção do substrato material do consenso das massas em relação ao poder. Se o substrato difere da sua representação ideológica no discurso do Estado, não é, contudo, redutível à mera propaganda (POULANTZAS, 2015, p. 30).

A essa linha de raciocínio se soma o fato de que a representação do Estado pelo binômio repressão-ideologia pode levar a uma confusão muito recorrente acerca da ideologia dominante: a de identificar a ideologia de Estado como "mero encobrimento ou dissimulação das metas do Estado, que produziria um discurso unificado, permanentemente mistificador, que só progrediria envolto em segredo e sempre dissimulado" (POULANTZAS, 20I5, p. 30).

Entendemos que, nesse ponto, a confusão se concretizaria ao não se perceber que a ideologia e o discurso têm seu limite na função de organização que o Estado proporciona à classe dominante, função essa que supera o efeito de inversão-encobrimento típico da ideologia capitalista. Quando a função da ideologia assume o papel apenas de obstáculo ao conhecimento da classe subalterna, o Estado abandona uma de suas funções mais importantes, a de organizar a classe dominante, e, com isso, põe em risco a própria dominância daquela classe ou fração de classe. Conforme o autor grego, o papel de organizador em relação às classes dominantes consiste também em "dizer, formular, declarar abertamente as táticas de reprodução de seu poder" (POULANTZAS, 20I5, p. 30). Essa declaração aberta, esse discurso, faz parte do que o autor grego chama de "espaço cênico" do Estado e da representação dessas classes (a cena política), mas não configura como um discurso unificado e sim como vários discursos fragmentados, a depender de onde eles se encontram nos diversos aparelhos de 
Estado e a que classe ou fração de classe se destinam. Esse discurso é, em relação às classes dominantes e suas frações, e às vezes também às classes de apoio, um "discurso-confissão de organização”.

Nesse sentido, o discurso é dirigido a todas as classes, para cumprir funções distintas, a depender de quem "recebe" o discurso ou os fragmentos discursivos do Estado.

O índice de ideologização do discurso e, também, das práticas materiais do Estado é, portanto, flutuante, variável e diversificado segundo as classes e frações de classe às quais se dirige o Estado e sobre as quais age. A verdade do poder escapa frequentemente às massas populares, não porque o Estado a esconda, mascare expressamente; e sim porque, por razões infinitamente mais complexas, as massas não conseguem compreender o discurso do Estado às classes dominantes (POULANTZAS, 20I5, p. 3I).

Quando um governo social-democrata declara, por exemplo, que o Estado fará uma "aliança entre os trabalhadores e os empresários" para o crescimento econômico, o discurso está sendo dirigido a ambas as classes fundamentais. Uma interpretação que se pode fazer dele é de que o Estado, ao se dirigir aos "empresários" (o capital), está declarando que as condições relativas às relações de trabalho não serão alteradas, e, por outro lado, está declarando à classe trabalhadora que as condições de exploração do trabalho serão postas em um contexto de cooperação e igualdade nas negociações.

Interpretamos que o "índice de ideologização do discurso" a que se refere Poulantzas diz respeito, primeiramente, a quanto o discurso corresponde à ocultação-inversão das relações de produção. Em segundo lugar, diz algo sobre a natureza relacional da ideologia e do próprio discurso político como partes integrantes das práticas de Estado. Ao se reportar a uma ideologia, constituída por meio de elementos de diversas ideologias que não a dominante, o discurso político atua sobre cada classe ou fração de maneira a se reportar àquele aspecto com que cada grupo mais se identifica. Dessa forma, esse processo discursivo implica que cada classe ou fração compreenda o discurso político de forma particular, mesmo que partindo das mesmas bases discursivas. Isso nos remete ao que o autor chama de "razões infinitamente mais complexas" para que as massas não compreendam o discurso de Estado dirigido à classe dominante. Ocorre que, na verdade, nem mesmo a classe dominante poderia compreender o discurso dirigido à classe subalterna. Às razões mencionadas por Poulantzas, entendemos que se deve somar uma última, que diz respeito especialmente ao que Althusser chamou de interpelação ideológica, e que Poulantzas não menciona em seu trabalho. A esse respeito, Laclau (1977) observa:

É estranho que Poulantzas, que opera no quadro geral da problemática althusseriana, não tenha retido a contribuição mais importante e específica de Althusser para o estudo das ideologias: a concepção de que a função básica 
de toda ideologia é interpelar/constituir os indivíduos como sujeitos (LACLAU, I977, p. IOO, tradução nossa).

A interpelação ideológica, como formulada por Althusser, corresponde a uma das funções da ideologia, de constituir indivíduos em sujeitos e assim identificá-los em determinada formação ideológica. Conforme o autor, as práticas atuam sobre o sujeito de forma a constituí-lo como tal, de modo que "a categoria de sujeito é constitutiva de toda a ideologia [...], mas só é constitutiva de toda a ideologia na medida em que toda ideologia tem por função (que a define) 'constituir' os indivíduos concretos em sujeitos" (ALTHUSSER, I982, p. 94). Significa dizer que, com essa interpelação, o sujeito é assujeitado pela ideologia por meio de uma prática e, com isso, se reconhece - e é reconhecido - em determinada posição no mundo. Em palavras de Althusser:

Sugerimos então que a ideologia "age" ou "funciona" de tal forma que "recruta" sujeitos dentre os indivíduos (ela os recruta a todos), ou "transforma" os indivíduos em sujeitos (ela os transforma a todos) através dessa operação muito precisa que chamamos interpelação, que pode ser entendida como o tipo mais banal de interpelação policial (ou não) cotidiana: "Ei, você aí!" (ALTHUSSER, 1982, p. 99).

Por essa dinâmica, todo indivíduo recebe como evidente aquilo que vê, o que diz e até mesmo quem "é", no sentido de sua colocação social. Isso pode ser visualizado em qualquer tipo de interpelação, e muito claramente no discurso (ou discursos) de Estado na cena política. A ideologia atuando sobre os discursos produz os mesmos efeitos que a interpelação aos sujeitos: o efeito da evidência dos sentidos (o que o discurso significa) e dos sujeitos (o que é o sujeito). Em palavras de Althusser (I982, p. 95): Como todas as evidências, incluindo as que fazem com que uma palavra "designe uma coisa" ou "possua uma significação" (portanto incluindo as evidências da "transparência" da linguagem), essa "evidência" de que eu e você somos sujeitos - e que esse fato não constitui problema — é um efeito ideológico, o efeito ideológico elementar.

Na reação de "evidência" é que reconhecemos, segundo o autor, a função de reconhecimento ideológico, que é uma das funções da ideologia. Esse reconhecimento ideológico é que desde sempre nos faz sujeitos. Como nos mostra Pêcheux (I988), na comunicação, a relação que se estabelece entre o "eu" e o "tu" é marcada pela ilusão da evidência do sujeito. Essa ilusão é ideológica na medida em que, para o autor, ambos os sujeitos pensam saber o que são, a quem estão se referindo, e, por consequência, acreditam saber qual é o sentido do discurso. Isso se relaciona, para o autor, à dissolução do caráter material do sentido. A interpelação a que Althusser se refere, no processo discursivo, cria essa evidência do sentido e apaga seu caráter de classe, criando a ilusão de que o sentido do discurso é algo dado e não algo relacionado à estrutura social. 
Como nos mostra

Pêcheux (1988), na

comunicação, a relação

que se estabelece

entre o "eu” e o "tu” é

marcada pela ilusão da

evidência do sujeito.

Essa ilusão é ideológica

na medida em que,

para o autor, ambos os

sujeitos pensam saber

o que são, a quem

estão se referindo,

e, por consequência, acreditam saber qual é

o sentido do discurso
Ainda que Poulantzas não utilize expressamente o conceito althusseriano de interpelação, compreendemos que o autor acaba por o incorporar em sua interpretação, por exemplo, do discurso (ou dos discursos) de Estado, como referimos antes, e, por consequência, na sua visão geral sobre a ideologia. Isso porque, se em sua obra inicial a ideologia opera, no plano do imaginário, em favor da função de coesão do Estado - por meio da ocultação, da dissimulação, da inversão das relações reais de classe -, ela o faz necessariamente por meio do mecanismo de interpelação dos sujeitos.

\section{CONCLUSÃO}

Neste artigo buscamos discutir elementos teóricos para uma interpretação ampliada do conceito de ideologia dominante na formação social capitalista. Por meio dos fundamentos identificados na revisão bibliográfica sobre o tema, procuramos analisar criticamente os sentidos atribuídos à ideologia, particularmente quanto às suas funções e efeitos para a análise da política e do Estado. Além disso, destacamos alguns pontos a serem considerados para uma compreensão ampliada do conceito de ideologia dominante e sua análise na formação social capitalista.

Ao longo do estudo identificamos que, particularmente no campo da política e do Estado - e especialmente a partir das contribuições de Marx, Engels e Poulantzas -, a ressignificação do conceito de ideologia permite que o compreendamos de forma ampliada por meio do complexo de características que o compõem e de diferentes níveis analíticos, conforme apresentam os autores estudados.

A compreensão ampliada do conceito de ideologia dominante não se confunde com uma abordagem generalista, com uma simples aglutinação de elementos teórico-conceituais. Pelo contrário, consiste na utilização crítica de algumas características, por vezes com retificações mais ou menos expressivas, necessárias para a análise aprofundada das relações sociais sob as lentes da ideologia. Ela se apresenta ampliada, justamente, por agregar diversas características e efeitos que compreendem sua ressignificação ao longo do tempo (dissimulação, inversão, conjunto de prá- 
ticas e valores de classe, representações, formas imaginárias, mundo “vivido", práticas sociais etc.).

A ideologia dominante, para Poulantzas, aparece como uma síntese de suas ressignificações históricas. Isso nos permite pensá-la de forma ampliada, para analisar, compreender e explicar as relações ideológicas como um fenômeno complexo. No plano da análise da região ideológica (jurídica), esse conceito assume certas regularidades na obra de Poulantzas: as funções de ocultação, de dissimulação e de inversão das relações de classe e de universalização de interesses particulares. Já quanto a suas práticas concretas, o autor compreende que a ideologia atende a um critério relacional, ligado à conjuntura da luta de classes.

Entendemos que a ideologia dominante, nos termos em que Poulantzas a analisa, principalmente em suas obras Poder político e classes sociais e O Estado, o poder, o socialismo, apresenta aspectos fundamentais para uma compreensão ampliada do conceito. Nessa primeira obra, a ideologia se apresenta como um pressuposto estrutural, compreendida por meio de seus efeitos no Estado capitalista. Já na segunda obra mencionada, com a definição do Estado como uma relação social, a ideologia também é apresentada sob uma abordagem ligada à prática social, na conjuntura de classes. Nesse caso, entretanto, a ideologia dominante se apresenta também como um "índice" relacionado à conjuntura da luta política. Nesse sentido, ela está sujeita à ação das classes sociais em luta de forma muito mais clara do que em Poder político e classes sociais. No mesmo sentido em que na obra O Estado, o poder, o socialismo o Estado é visto como estratégico para a mudança social, também a ideologia assume esse caráter — já está imersa no aparelho do Estado.

Esses elementos, conjugados a outros referentes à ressignificação histórica do conceito, nos possibilitam avançar para uma interpretação ampliada do conceito de ideologia dominante e nos auxiliam no exame da dimensão ideológica da luta social como um objeto de estudo complexo. Dessa forma, a modo de síntese, compreendemos que para uma interpretação ampliada do conceito de ideologia dominante são necessárias pelo menos duas dimensões de análise. Uma primeira que compreenda seus pressupostos estruturais (efeitos de isolamento e unidade), e outra que identifique e analise suas práticas concretas (o discurso político, as práticas jurídicas, as relações de trabalho etc.) numa formação social determinada.

\footnotetext{
* Doutor e pós-doutorando em Ciência Política pela Universidade Federal do Rio Grande do Sul (UFRGS).

** Doutor em Economia Política Internacional pela Universidade Federal do Rio de Janeiro (UFRJ). Professor da Escola de Administração e do Programa de PósGraduação em Ciência Política da UFRGS.
}

Texto recebido em fevereiro de 2021; aprovado em fevereiro de 2021 
ALMEIDA, Lúcio Flávio R. Ideologia, ideologias, lutas de classes: Althusser e os aparelhos ideológicos (de Estado). In: PINHEIRO, Jair. (Org.). Ler Althusser. Marília; São Paulo: Oficina Universitária; Cultura Acadêmica, 2016. p. 71-96.

ALTHUSSER, Louis. Ideologia e aparelhos ideológicos do Estado. Lisboa: Editorial Presença; Martins Fontes, 1982.

Por Marx. Campinas: Editora Unicamp, 2015.

Sobre a reprodução. Petrópolis: Vozes, 1999.

EAGLETON, Terry. Ideologia: uma introdução. São Paulo: Boitempo, 2019.

ENGELS, Friedrich. Engels to Franz Mehring. In: MARX, Karl; ENGELS, Friedrich; FEUER, Lewis Samuel. Basic Writings on Politics and Philosophy. New York: Doubleday, 1969. p. 407-409.

KONDER, Leandro. A questão da ideologia. São Paulo: Companhia das Letras, 2002.

LACLAU, Ernesto. Politics and ideology in Marxist theory: capitalism, fascism, populism. London: NLB, 1977.

LARRAÍN, Jorge. El concepto de ideología. Santiago: LOM Ediciones, 2008.

. Ideologia. In: BOTTOMORE, Tom (Org.). Dicionário do pensamento marxista. Rio de Janeiro: Zahar, 1988. p. 293-297.

LÊNIN, Vladimir llitch. Obras completas. Madrid: Akal, 1976.

LÖWY, Michael. Ideologias e ciência social: elementos para uma análise marxista. São Paulo: Cortez, 1991.

MANNHEIM, Karl. Ideologia e utopia: introdução à sociologia do conhecimento. Porto Alegre: Globo, 1950.

MARX, Karl. O 18 de brumário de Luís Bonaparte. São Paulo: Boitempo, 2011.

; ENGELS, Friedrich. A ideologia alemã. São Paulo: Boitempo, 2007.

MÉSZÁROS, István. Transformações materiais e formas ideológicas. In:

Estrutura social e formas de consciência II: a dialética da estrutura e da história. São Paulo: Boitempo, 2011. p. 105-176.

MOTTA, Luiz Eduardo. A favor de Althusser: revolução e ruptura na teoria marxista. Rio de Janeiro: Gramma; Faperj, 2014.

Poulantzas e o direito. Dados, v. 53, n. 2, p. 367-403, 2010.

PÊCHEUX, Michel. Língua e ideologia. In: óbvio. Campinas: Editora Unicamp, 1988. p. 87-94.

POULANTZAS, Nicos. O Estado, o poder, o socialismo. São Paulo: Paz e Terra, 2015.

Poder político e classes sociais. Campinas: Editora Unicamp, 2019.

Repères, hier et aujourd'hui: textes sur l'État. Paris: François Maspero, 1980.

SAMPEDRO, Francisco. A teoria da ideologia em Althusser. In: NAVES, Márcio Bilharinho (Org.). Presença de Althusser. Campinas: Unicamp; IFCH, 2010. p. 31-52.

SILVA, Ludovico. La plusvalía ideológica. Caracas: Fundarte, 2017.

Teoría y práctica de la ideología. México: Nuestro Tiempo, 1978.

THOMPSON, John B. Ideologia e cultura moderna: teoria social crítica na era dos meios de comunicação de massa. Petrópolis: Vozes, 2011.

ŽlŽEK, Slavoj. O espectro da ideologia. In: Um mapa da ideologia. Rio de Janeiro: Contraponto, 1996. p. 7-38. 